\section{Mortality associated with community-acquired cephalosporin-resistant Escherichia coli in patients admitted to a district hospital in a resource-limited setting}

\author{
Gerardo Alvarez-Uria, ${ }^{1}$ \\ Uvummala Priyadarshini, ${ }^{2}$ \\ Praveen K. Naik, ${ }^{1}$ Manoranjan Midde, \\ Raghuprakash Reddy ${ }^{2}$ \\ 'Department of Infectious Diseases; \\ 2Department of Microbiology, Rural \\ Development Trust Hospital, Bathalapalli, \\ Anantapur district, AP, India
}

\section{Abstract}

Studies performed in developed countries have shown that infections by third generation cephalosporin resistant Escherichia coli (G3CREC) are associated with increased mortality, but data from developing countries are scarce. In this observational study, we collected clinical and microbiological information of 194 patients admitted to a district hospital in India who had community-acquired isolation of Escherichia coli. The proportion of patients with G3CREC was 79.4\%. In a multivariable logistic regression analysis, factors associated with 21-day mortality were isolation from a normally sterile site, HIV infection and isolation of G3CREC. Strains of Escherichia coli isolated from normally sterile sites had lower levels of resistance to quinolones and beta-lactam antibiotics. The proportion of meropenem and ciprofloxacin resistance was $11.1 \%$ and $80.9 \%$ respectively. The high proportion of G3CREC in the community and the association of G3CREC with 21-day mortality indicate that G3CREC is a major public health problem in developing countries.

\section{Introduction}

Rapid development of antimicrobial resistance by common bacteria is a major concern worldwide. Studies from developed countries have shown that infections produced by resistant microorganisms are associated with increased mortality and increased cost for health care systems. ${ }^{1}$ Developing countries bear most of the common bacterial infection burden worldwide, ${ }^{2}$ but data from resource limited settings are scarce. ${ }^{3}$

Recent studies have predicted a shift in the burden of antimicrobial resistance from Gram positive to Gram negative infections. ${ }^{1}$ Escherichia coli is the most common cause of urinary tract infections and one of the leading cause of blood stream infection worldwide. ${ }^{4}$ For Escherichia coli, third generation cephalosporin resistance is associated with resistance to other antimicrobials and can be used as a marker of multidrug-resistance. In Europe, third generation cephalosporin resistant Escherichia coli (G3CREC) has shown to increase mortality and hospital stay in patients from tertiary hospitals with blood stream infection. ${ }^{5}$ India is a highly populated country with nearly $69 \%$ of people living in rural areas. ${ }^{6}$ Previous studies have shown high levels of G3CREC in India. ${ }^{7}$ However, the majority of these studies were performed in tertiary hospitals in urban areas, so the results of these studies may reflect local prevalence of resistant bacteria related to high antibiotic pressure in these sites. The prevalence of antibiotic resistant Escherichia coli in the community of rural areas of India is not well known. The aim of this study is to describe the prevalence of G3CREC and to investigate the effect of G3CREC on the mortality of patients admitted to a district hospital in a rural area of India.

\section{Materials and Methods}

\section{Setting}

The study was performed in the Bathalapalli Rural Development Trust Hospital, a non-profit private district hospital in Andhra Pradesh, India. The hospital belongs to a non-governmental organization that provides free consultation and medicines at reduced cost to people of low socio-economic status. The hospital is fully computerized and, as a routine, clinical and microbiological information of the patients is introduced in a hospital database.

\section{Study design}

For this study we selected cases admitted to the hospital with isolation of Escherichia coli from any clinical specimen from $24^{\text {th }}$ March 2011 to $18^{\text {th }}$ March 2012. Of this group, patient who met criteria for having a communityacquired isolation of Escherichia coli were included in the study: isolation in the first $48 \mathrm{~h}$ of admission and no previous hospital admission in the last 90 days. ${ }^{8}$ Antimicrobial susceptibilities were performed in the Microbiology Laboratory of the hospital using disk diffusion testing according to recommendations of the Clinical Laboratory Standard Institute. ${ }^{9}$ All strains where tested for extended spectrum beta-lactamase (ESBL) production by double disk synergy test. G3CREC was defined when the antibiogram shown resistance to cefotaxime. ${ }^{10}$ The primary end-point of the study
Correspondence: Gerardo Alvarez-Uria, Department of Infectious Diseases, Bathalapalli Rural Development Trust Hospital, Kadiri Road, Bathalapalli 515661, Anantapur District, Andhra Pradesh, India. Fax/Tel: +918559242316

E-mail: gerardouria@gmail.com

Key words: Escherichia coli, mortality, drug resistance, developing countries.

Contributions: GAU, UP, PKN, MM, RR, study concept and design, manuscript preparation; UP, data acquisition.

Conflict of interests: the authors declare no potential conflict of interests.

Received for publication: 13 May 2012.

Revision received: 12 July 2012 .

Accepted for publication: 29 July 2012 .

This work is licensed under a Creative Commons Attribution NonCommercial 3.0 License (CC BYNC 3.0).

(C) Copyright G. Alvarez-Uria et al., 2012

Licensee PAGEPress, Italy

Clinics and Practice 2012; 2:e76

doi:10.4081/cp.2012.e76

was to compare the 21-day mortality of patients who had G3CREC with patient who had a cephalosporin-susceptible Escherichia coli isolation. Blood, bone marrow, cerebrospinal fluid, ascitic fluid and pleural fluid were considered as normally sterile site (NSS) isolations.

\section{Statistical analysis}

Confidence intervals for proportions were estimated utilizing the Wilson method. ${ }^{11}$ Variables that could be related to increased mortality as age, sex, HIV infection and NSS isolation were introduced in a multivariable logistic regression analysis model to assess the effect of having G3CREC isolation on 21day mortality. We used Kaplan-Meier survival curves to describe the mortality of patients with and without G3CREC. Time was measured from the date of admission to the date of death in patients who died, or from the date of admission to the last visit date or the date of discharge, whatever occurred last. Statistical analysis was performed using Stata Statistical Software (Stata Corporation. Release 11. College Station, TX, USA).

\section{Results}

During the period of the study, Escherichia coli was identified in 219 specimens from 194 patients admitted to the hospital. Antimicrobial resistance to antibiotics by specimen type is 
presented in Table 1. Nitrofurantoin (only tested in urinary specimens), amikacin, chloramphenicol, meropenem and gentamicin had low levels of resistance. The proportion of specimens with G3CREC was 78.1\% (95\% confidence interval [CI], 72.1-83.1). The proportion of meropenem and ciprofloxacin resistance was $11.1 \%$ (95\% CI, 7.6-16) and 80.9\% (95\% CI, 75.185.6) respectively. Colistin was tested only for 17 isolations and all of them were susceptible. Compared to other sites, isolations from NSS had lower levels of resistance to ciprofloxacin $(\mathrm{P}=0.019)$, cefotaxime $(\mathrm{P}=0.003)$, ceftazidime $(\mathrm{P}=0.004), \quad$ cefepime $\quad(\mathrm{P}=0.011) \quad$ and piperacillin-tazobactam $(\mathrm{P}<0.001)$.

The proportion of patients with G3CREC was 79.4\% (95\% CI, 73.1-84.4) and the global 21day mortality was $13.4 \%$ (95\% CI, 9.3-18.9). 21day mortality was $5 \%(95 \% \mathrm{CI}, 1.4-16.5)$ in patients with cephalosporin susceptible Escherichia coli and 15.6\% (95\% CI, 10.7-22.1) in patients with G3CREC. Among the 154 patients with G3CREC, 126 (81.8\%, 95\% CI 7587.1) had an ESBL producing Escherichia coli. Baseline characteristics of the patients and multivariable analysis of factors associated with 21-day mortality are presented in Table 2. Factors significantly related to 21-day mortality were HIV infection, isolation from a NSS and isolation of G3CREC. Kaplan Meier survival curves of patients with and without G3CREC are presented in Figure 1.

\section{Discussion}

The results of this study show the high proportion of resistance to quinolones, penicillins and cephalosporins in strains of Escherichia coli isolated from the community. Other Indian studies have shown high levels of ESBL producing Escherichia coli, ranging from $63 \%$ to $79 \%$ in different settings and specimen types. ${ }^{12-14}$ However, the rise of G3CREC is not an exclusive Indian phenomenon. In a study that involved 31 European countries, it was predicted an exponential increase in the number of bacteraemias produced by G3CREC in Europe. ${ }^{1}$ Reports of resistant Escherichia coli have also been recently described in Africa. ${ }^{15,16}$ Genes that encode third generation cephalosporin resistance are easily spread within health-care facilities, ${ }^{17}$ but also among travelers to countries with high levels of G3CREC. ${ }^{18,19}$ G3CREC is now a major public health problem in India, but we will probably see a rapid spread of G3CREC in other parts of the world in the near future.

Our results indicate that there is an association between isolation of G3CREC and 21-day mortality in patients admitted to a district hospital in India. Not surprising, the odds ratio for mortality found in this study was higher than the odds ratios for mortality found in other
Table 1. Percentage of antibiotic resistance by clinical specimen.

\begin{tabular}{lcccccc} 
Antibiotic & $\begin{array}{c}\text { Urine } \\
(\mathrm{N}=113)\end{array}$ & $\begin{array}{c}\text { NSS } \\
(\mathrm{N}=21)\end{array}$ & $\begin{array}{c}\text { Pus } \\
(\mathrm{N}=42)\end{array}$ & $\begin{array}{c}\text { Sputum } \\
(\mathrm{N}=11)\end{array}$ & $\begin{array}{c}\text { Others } \\
(\mathrm{N}=32)\end{array}$ & $\begin{array}{c}\text { Total } \\
(\mathbf{N}=219)\end{array}$ \\
Nitrofurantoin & 0.9 & - & - & - & - & 0.9 \\
Amikacin & 1.8 & 0.0 & 4.8 & 9.1 & 6.3 & 3.3 \\
\hline Gentamicin & 22.5 & 9.5 & 19.0 & 18.2 & 15.6 & 19.4 \\
Chloramphenicol & 6.4 & 0.0 & 16.7 & 0.0 & 20.0 & 9.5 \\
\hline Ciprofloxacin & 86.2 & 61.9 & 73.8 & 90.9 & 81.3 & 80.9 \\
Cotrimoxazole & 79.6 & 61.9 & 65.0 & 80.0 & 70.0 & 73.7 \\
\hline Cefotaxime & 85.0 & 52.4 & 71.4 & 90.9 & 75.0 & 78.1 \\
Ceftazidime & 83.6 & 52.4 & 71.4 & 90.9 & 74.2 & 77.2 \\
\hline Cefepime & 82.6 & 55.0 & 73.8 & 90.9 & 75.0 & 77.6 \\
Piperacillin-tazobactam & 100.0 & 57.1 & 70.0 & 90.0 & 77.4 & 83.9 \\
\hline Amoxicillin-clavulanate & 92.9 & 81.0 & 82.9 & 100.0 & 90.6 & 89.9 \\
Meropenem & 8.1 & 14.3 & 19.5 & 0.0 & 12.5 & 11.1 \\
\hline
\end{tabular}

NSS, normally sterile site (blood, bone marrow, cerebrospinal fluid, ascitic fluid and pleural fluid).

Table 2. Baseline characteristics and factors associated with 21-day mortality.

\begin{tabular}{|c|c|c|c|c|c|}
\hline \multirow{3}{*}{\multicolumn{2}{|c|}{$\begin{array}{r}\text { Baseline characteristics } \\
\text { N (\%) }\end{array}$}} & \multicolumn{2}{|c|}{ 21-day mortality } & \multirow{2}{*}{\multicolumn{2}{|c|}{$\begin{array}{l}\text { 21-day mortality } \\
\text { multivariable analysis }\end{array}$}} \\
\hline & & \multirow{2}{*}{$\begin{array}{c}\text { No }(\mathrm{N}=168) \\
\mathrm{N}(\%)\end{array}$} & \multirow{2}{*}{$\begin{array}{c}\text { Yes }(\mathrm{N}=26) \\
\mathrm{N}(\%)\end{array}$} & & \\
\hline & & & & aOR & P-value \\
\hline Age (years) & $35.3(25-50)^{*}$ & $35(24-50) *$ & $40(32.7-49) *$ & $1.03(1-1.07)$ & 0.072 \\
\hline Female & $72(37.1)$ & 65 (38.7) & $7(26.9)$ & $0.78(0.28-2.19)$ & 0.643 \\
\hline HIV infection & $80(41.2)$ & $59(35.1)$ & $21(80.8)$ & $10.89(3.26-36.42)$ & $<0.001$ \\
\hline Isolation from a NSS & S $19(9.8)$ & $13(7.7)$ & $6(23.1)$ & $11.96(2.47-57.97)$ & 0.002 \\
\hline G3CREC & $154(79.4)$ & $130(77.4)$ & $24(92.3)$ & $8.24(1.19-57.28)$ & 0.033 \\
\hline
\end{tabular}

*, Median (interquartile range); aOR, adjusted odds ratio; NSS, normally sterile site; G3CREC, third generation cephalosporin resistant Escherichia Coli.

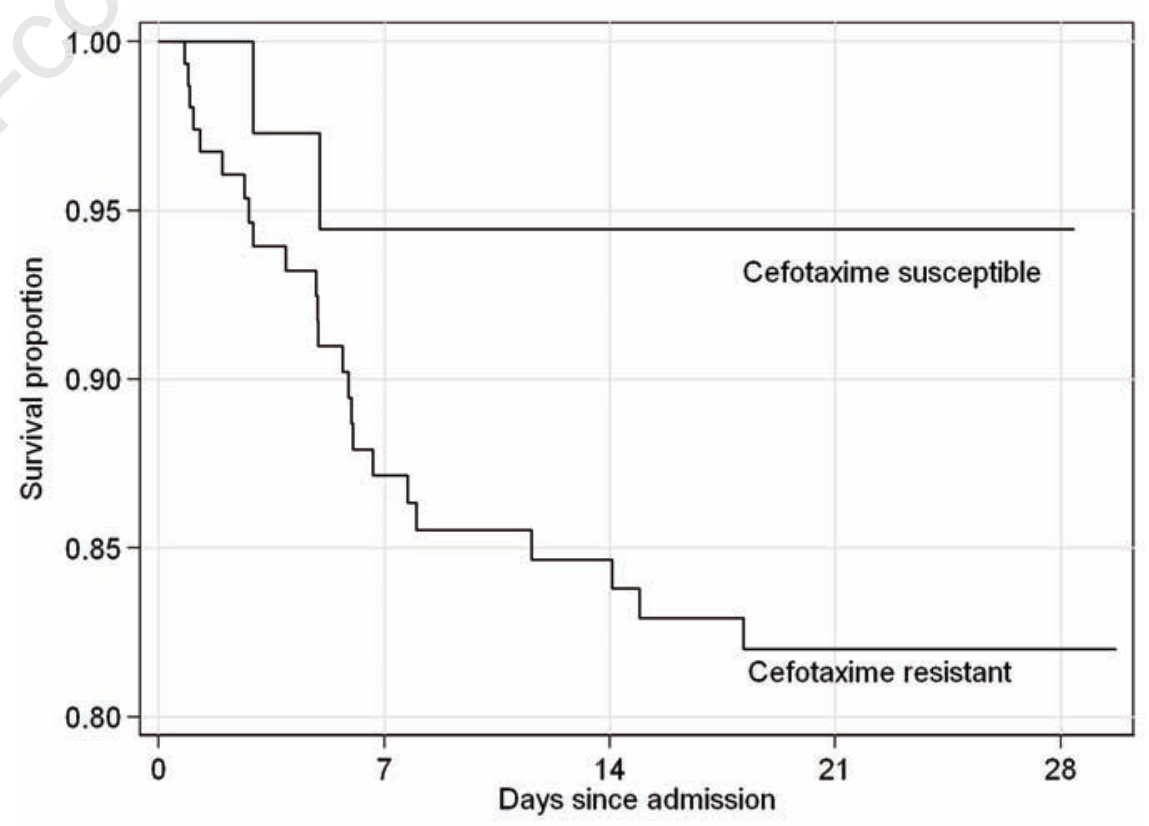

Figure 1. Kaplan Meier survival curves of patients admitted to the hospital with Escherichia coli isolation. Escherichia coli isolation.

[Clinics and Practice 2012; 2:e76] 
studies from tertiary hospital in Europe and in South Korea where resources are not so limited. ${ }^{5,20}$ Although the spread G3CREC affects both developed and developing countries, it will cause higher mortality in resource-limited settings because of the scarcity of laboratories capable of providing antimicrobial susceptibilities and the high cost of effective antibiotics against G3CREC.

Interesting, isolations from NSS had lower proportion of antibiotic resistance to ciprofloxacin and beta-lactam antibiotics. It has been described that the development of antibiotic resistance by common bacteria bears a cost in terms of reduced fitness and virulence. ${ }^{21}$ The lower proportion of G3CREC in specimens from NSS could be explained by the loss of virulence of Escherichia coli strains that develop resistance to these antibiotics. ${ }^{21}$

The spread of G3CREC should have important implication for the management of urinary tract infection and suspected Escherichia coli blood stream infections. The most commonly used antibiotics in non-complicated urinary tract infections (cotrimoxazole, fluoroquinolones, aminopenicillins and cephalosporins) are frequently not effective against G3CREC. ${ }^{7}$ In our study, nitrofurantoin and chloramphenicol were more frequently susceptible than other antibiotics because they are not commonly used, so these antibiotics could be utilized for the treatment of non-complicated urinary tract infection. Aminoglycosides and carbapenems should preferably be reserved for empirical treatment of severe infections. However, there is an important concern about the future therapeutic options for Escherichia coli infections because of the scarcity of new antibiotics for treating Gram negative bacteria in the pipeline.22

The study has some limitations. We did not collect clinical data for distinguishing infection from colonization in some of the isolations from non-sterile sites. In addition, we did not collect clinical information of present morbidities at the moment of admission. It is possible that patients with G3CREC had unknown risk factors not included in the multivariable model that could modify the results of the study. However, the possibility of confounders related to having G3CREC isolation is unlikely, because the study was performed in a rural area, where referrals from other health-care centers are rare, and we excluded isolations performed after $48 \mathrm{~h}$ of admission and patients admitted in the previous 90 days.

\section{Conclusions}

The results of this study indicate that a high proportion of community-acquired isolations of Escherichia coli are resistant to multiple antibiotics and having G3CREC isolation is associated with higher risk of death in this Indian setting. If these findings are confirmed by other studies in resource-limited setting, the emergence of G3CREC could be a major public health threat in developing countries.

\section{References}

1. de Kraker MEA, Davey PG, Grundmann H, on behalf of the BURDEN study group. Mortality and hospital stay associated with resistant Staphylococcus aureus and Escherichia coli Bacteremia: estimating the burden of antibiotic resistance in Europe. PLoS Med 2011;8:e1001104.

2. WHO. World Health Statistics 2011. Available at: http://www.who.int/gho/publications/world_health_statistics/2011/en/in dex.html Accessed: May 7, 2012.

3. WHO. The evolving threat of antimicrobial resistance - Options for action. 2012. Available at: http:/www.who.int/ patientsafety/implementation/amr/publication/en/i ndex.html Accessed: March 17, 2012.

4. Biedenbach DJ, Moet GJ, Jones RN. Occurrence and antimicrobial resistance pattern comparisons among bloodstream infection isolates from the SENTRY Antimicrobial Surveillance Program (1997-2002). Diagn Microbiol Infect Dis 2004;50:59-69.

5. de Kraker MEA, Wolkewitz M, Davey PG, et al. Burden of antimicrobial resistance in European hospitals: excess mortality and length of hospital stay associated with bloodstream infections due to Escherichia coli resistant to third-generation cephalosporins. J Antimicrob Chemother 2011;66:398-407.

6. Office of The Registrar General \& Census Commissioner. Census of India 2011.

7. Global Antibiotic Resistance Partnership (GARP) - India Working Group. Rationalizing antibiotic use to limit antibiotic resistance in India. Indian J Med Res 2011;134:281-94.

8. Friedman ND, Kaye KS, Stout JE, et al. Health care--associated bloodstream infections in adults: a reason to change the accepted definition of communityacquired infections. Ann Intern Med 2002; 137:791-7.

9. Clinical and Laboratory Standards Institute. Performance standard for antimicrobial disk susceptibility tests. 2009.

10. Mattner F, Bange F-C, Meyer E, et al. Preventing the spread of multidrug-resistant gram-negative pathogens. Dtsch Arztebl Int 2012;109:39-45.
11. Agresti A, Coull BA. Approximate is better than "exact" for interval estimation of binomial proportions. Am Stat 1998;52: 119-26.

12. Sood S, Gupta R. Antibiotic resistance pattern of community acquired uropathogens at a tertiary care hospital in Jaipur, Rajasthan. Indian $\mathrm{J}$ Commun Med 2012;37:39-44.

13. Eshwarappa M, Dosegowda R, Aprameya IV, et al. Clinico-microbiological profile of urinary tract infection in south India. Indian J Nephrol 2011;21:30-6.

14. Hawser SP, Bouchillon SK, Hoban DJ, et al. Emergence of high levels of extendedspectrum-beta-lactamase-producing gramnegative bacilli in the Asia-Pacific region: data from the Study for Monitoring Antimicrobial Resistance Trends (SMART) program, 2007. Antimicrob Agents Chemother 2009;53:3280-4.

15. Chouchani C, Marrakchi R, El Salabi A. Evolution of -lactams resistance in Gramnegative bacteria in Tunisia. Crit Rev Microbiol 2011;37:167-77.

16. Muvunyi CM, Masaisa F, Bayingana C, et al. Decreased susceptibility to commonly used antimicrobial agents in bacterial pathogens isolated from urinary tract infections in Rwanda: need for new antimicrobial guidelines. Am J Trop Med Hyg 2011;84:923-8.

17. Woerther P-L, Angebault C, Jacquier H, et al. Massive increase, spread, and exchange of extended spectrum -lactamase-encoding genes among intestinal Enterobacteriaceae in hospitalized children with severe acute malnutrition in Niger. Clin Infect Dis 2011;53:677-85.

18. Freeman JT, McBride SJ, Heffernan H, et al. Community-onset genitourinary tract infection due to CTX-M-15-Producing Escherichia coli among travelers to the Indian subcontinent in New Zealand. Clin Infect Dis 2008;47:689-92.

19. Peirano G, Laupland KB, Gregson DB, Pitout JDD. Colonization of returning travelers with CTX-M-producing Escherichia coli. J Travel Med 2011;18:299-303.

20. Kang C-I, Song J-H, Chung DR, et al. Risk factors and treatment outcomes of community-onset bacteraemia caused by extended-spectrum beta-lactamase-producing Escherichia coli. Int J Antimicrob Agents 2010;36:284-7.

21. Andersson DI, Hughes D. Antibiotic resistance and its cost: is it possible to reverse resistance? Nat Rev Microbiol 2010;8: 260-71.

22. Schultsz C, Geerlings S. Plasmid-mediated resistance in Enterobacteriaceae: changing landscape and implications for therapy. Drugs 2012;72:1-16. 